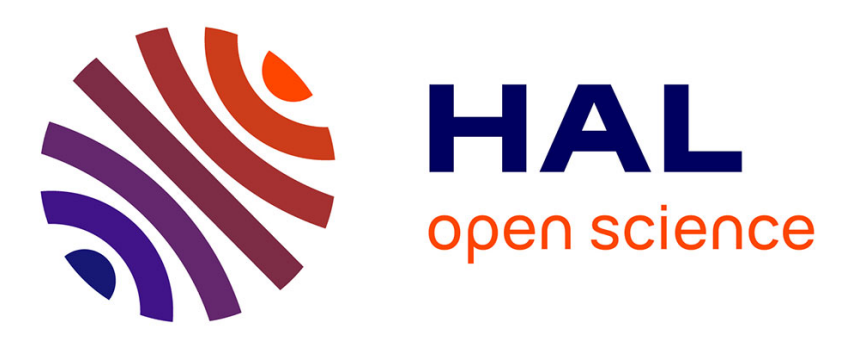

\title{
Midterm Recanalization after Arterial Embolization Using Hydrogel-Coated Coils versus Fibered Coils in an Animal Model
}

Audrey Fohlen, Julien Namur, Homayra Ghegediban, Alexandre Laurent, Michel Wassef, Jean-Pierre Pelage

\section{To cite this version:}

Audrey Fohlen, Julien Namur, Homayra Ghegediban, Alexandre Laurent, Michel Wassef, et al.. Midterm Recanalization after Arterial Embolization Using Hydrogel-Coated Coils versus Fibered Coils in an Animal Model. JVIR: Journal of Vascular and Interventional Radiology, 2019, 30, pp.940 - 948. 10.1016/j.jvir.2018.05.005 . hal-03484363

\section{HAL Id: hal-03484363 https://hal.science/hal-03484363}

Submitted on 20 Dec 2021

HAL is a multi-disciplinary open access archive for the deposit and dissemination of scientific research documents, whether they are published or not. The documents may come from teaching and research institutions in France or abroad, or from public or private research centers.
L'archive ouverte pluridisciplinaire HAL, est destinée au dépôt et à la diffusion de documents scientifiques de niveau recherche, publiés ou non, émanant des établissements d'enseignement et de recherche français ou étrangers, des laboratoires publics ou privés.

\section{(ㄷ)(1) $\$$}

Distributed under a Creative Commons Attribution - NonCommerciall 4.0 International 
Mid-Term Recanalization after Arterial Embolization Using Hydrogel-Coated coils versus Fibered Coils in an Animal Model

\author{
Audrey Fohlen, MD MSc (1) \\ Julien Namur, PhD (2) \\ Homayra Ghegediban, MSc (2) \\ Alexandre Laurent, MD PhD (3) \\ Michel Wassef, MD (4) \\ Jean-Pierre Pelage, MD PhD (1)
}

(1) Normandie University, UNICAEN, CEA, CNRS, ISTCT-CERVOxy, 14000 Caen, France

(2) Archimmed, 12 rue Charles de Gaulle 78350 Jouy-en-Josas

(3) Department of Neuroradiology, Hôpital Lariboisière, Université Paris 7, rue Ambroise Paré 75475 Paris Cedex 10, France

(4) Department of Pathology, Hôpital Lariboisière, Université Paris 7, rue Ambroise Paré 75475 Paris Cedex 10, France

Corresponding author: Jean-Pierre Pelage, Normandie University, UNICAEN, CEA, CNRS, ISTCT-CERVOxy, 14000 Caen, France pelage-jp@chu-caen.fr 
Mid-Term Recanalization after Arterial Embolization Using HydrogelCoated coils versus Fibered Coils in an Animal Model 


\section{Purpose:}

To compare angiographic and pathological effects (occlusion or recanalization) after embolization using hydrogel-coated coils (hydrocoils) and fibered coils in the renal and internal iliac arteries after 7 days, 1 month and 4 months in an animal model.

Materials and methods: Twelve sheep had one internal iliac and one renal artery randomly embolized using hydrocoils or fibered coils. Renal and internal iliac arteries were embolized using detachable 0.018-inch coils and pushable 0.035-inch coils, respectively. All animals had control angiography performed at 7 days, 1 month and 4 months to assess recanalization before sacrifice. Recanalization and inflammation were evaluated at pathology.

Results: At one month, $100 \%$ of the arteries embolized with hydrocoils were occluded versus $50 \%$ of those embolized with fibered coils $(\mathrm{p}=0.004)$. At 4 months, $80 \%$ of the arteries embolized with hydrocoils were occluded vs $25 \%$ of those embolized with fibered coils $(\mathrm{p}=0.01)$. Surface of vessel occlusion was significantly higher for iliac arteries $(96.7 \pm 8.9 \%)$ than for renal arteries $(94.2 \pm 5.3 \%)(\mathrm{p}=0.0076)$. Surface of occlusion of the renal arteries $(92.2$ $\pm 5.1 \%)$ was lower for fibered coils than for hydrocoils $(96.8 \pm 4.7 \%)(\mathrm{p}=0.0287)$. Surface percentage of thrombus was significantly lower for hydrocoils than for fibered coils $(p<0.0001)$. Surface percentage of thrombus was correlated with surface percentage of recanalization $(\mathrm{p}=0.0181)$.

Conclusion: After 4 months, $75 \%$ of the arteries embolized with fibered coils were recanalized vs $20 \%$ of those embolized with hydrocoils $(\mathrm{p}=0.01$ ). Reduced amount of thrombus after embolization with hydrocoils accounted for reduced rate of arterial recanalization. 


\section{Introduction}

Coils are extensively used to treat intra-cranial aneurysms and in the peripheral system to achieve a definitive occlusion (1-4). With coils a mechanical occlusion of the embolized vessel is achieved. The degree of luminal packing is the most important parameter for obtaining cross-sectional occlusion and reducing the risk of recanalization $(2,3,4)$. For peripheral embolization, fibered coils with Dacron or Nylon fiber bundles tied to the primary platinum coil enhance the thrombogenicity of the coil (3). Hydrogel-coated coils (hydrocoils) consist of a platinum coil coated with bioactive polymers that expand in contact with blood $(5,6)$. The use of hydrocoils has been reported mainly in neurointerventional procedures and more recently in the peripheral circulation (6-8). The interest of hydrocoils has been well established in the treatment of cerebral aneurysms both in animal models and in patients (5,9-11). This technology seems to be associated with lower recanalization rate because of a different mechanism of initial occlusion with reduced thrombus formation $(9,12-14)$.

The objectives of the present study were as follows:

To compare the angiographic effects (complete occlusion or recanalization) after embolization using detachable 0.018-inch and pushable 0.035-inch hydrocoils and fibered coils in 2 arterial territories (internal iliac arteries and renal arteries) after 7 days, 1 month and 4 months in the sheep animal model.

To evaluate the pathological aspects of the harvested specimen in the renal and internal iliac arteries after embolization using hydrocoils and fibered coils at 4 months in terms of recanalization.

To describe the embolization plug composition and the intensity of inflammatory reaction at pathology.

Material and Methods

All experiments were conducted according to European Community rules of animal care (EC 86/609) and approval from the institutional animal care committee was obtained. Two types of peripheral hydrocoils (Azur, Terumo, Japan) were used: 0.018-inch detachable coils 
and 0.035-inch pushable coils. Two types of fibered coils similar in diameter and length were used for comparison: 0.018 detachable fibered coils (Interlock, Boston Scientific, USA) and 0.035-inch pushable fibered coils (Nester, Cook, Denmark). All embolization procedures were performed by two experienced interventional radiologists (with 12 and 4 years of experience in embolization, respectively). The sheep model was selected because of numerous studies demonstrating the ability to perform superselective catheterization and embolization of various arteries $(14,15)$.

\section{Procedure}

Anesthesia was induced by means of intramuscular injection of sodium thiopental (Nesdonal). The animals were placed in the supine position and anesthetized with a mixture of $1.5 \%$ halothane and $98.5 \%$ oxygen and ventilated. End-tidal $\mathrm{CO}_{2}$ levels were maintained between 26 and $36 \mathrm{~mm} \mathrm{Hg}$. Peripheral arterial oxygen saturation was maintained at a level higher than 95\%. A 5-French vascular sheath was placed into the common femoral artery via standard Seldinger technique under sterile conditions after percutaneous arterial puncture and a 5-French Cobra-shaped catheter (Terumo, Japan) was used to as the primary angiographic catheter.

Success associated with embolization was defined by the ability of the operator to catheterize the target artery and achieve complete arterial occlusion (stasis). The middle segment of the posterior division of the internal iliac artery proximal to the bifurcation between the inferior and superior gluteal arteries was catheterized and embolized with pushable 0.035 coils using the 5-F catheter. Selective catheterization of the renal arteries was then performed using the 5$\mathrm{F}$ catheter. The middle segment of the renal artery proximal to the bifurcation was then embolized using detachable 0.018 microcoils through a microcatheter (Progreat 2.4-F or 2.7-F, Terumo, Japan) placed co-axially. Each animal had the right renal and the left internal iliac arteries embolized using either hydrocoils or fibered coils. The angiographic end-point assessed 10 minutes after embolization was complete occlusion (stasis). For the iliac artery, the diameter of the first coil was $6 \mathrm{~mm}$ with a 10-20 cm length. For the renal artery, the diameter was $8 \mathrm{~mm}$ with a 10-14 cm length applying appropriate oversizing with soft microcoils. The total number and total length $(\mathrm{cm})$ of coils used were recorded. All coils were used following the recommendations provided by the companies. All 0.035-inch coils were pushed using a 0.035inch standard Teflon wire. Detachable 0.018-inch hydrocoils were delivered through a large lumen microcatheter Progreat 2.7-F whereas detachable 0.018-inch fibered coils were delivered through a Progreat 2.4-F. 
Control angiograms were performed immediately after embolization and repeated at 7 days, 1 month and 4 months in all animals. Angiographic recanalization was evaluated with selective injections. A three-grade classification was used: complete occlusion, partial recanalization and complete recanalization.

Pathology

Sacrifice was performed after control angiography at 4 months. The animals were euthanized with an overdose of $60 \mathrm{mg} / \mathrm{kg}$ of pentobarbital.

Tissue specimens were examined macroscopically to identify the segments of artery containing the coils. After fixation in formaldehyde, all specimens were rinsed overnight in a steady stream of water. Then, the samples were dehydrated in a graded ethanol series (70-100\%) over a 7-day period and cleared in xylol for 24 hours. The cleared tissue was then impregnated stepwise with a mixture of xylol-methyl methacrylate, methyl methacrylate $0 \%$ and methyl methacrylate $1 \%$. The tissue samples were then placed into glass vials that contained a thin bottom layer of polymerized resin to facilitate sectioning. The glass vials were filled with a solution of methyl methacrylate $2 \%$ then tightly capped and placed in a thermostatic water bath at $17^{\circ} \mathrm{C}$ for 7 days to allow polymerization. The samples were placed at room temperature until the resin hardened. The glass vials were broken and the specimens were removed. The polymerized blocks were shaped and trimmed of excess plastic with a saw. Then, two $300 \mu \mathrm{m}$ thick sections were cut, one at the center of the block and the other a quarter of the way along it. Each section was glued to plastic slides, ground to approximately $100 \mu \mathrm{m}$ thickness, polished to an optical finish and stained with Stevenel blue and Van Gieson picro fuchsine. All obtained slices were digitized using a NanoZoomer Digital slide scanner (Hamamatsu, Japan).

The following parameters were assessed:

1. Vessel diameter (in $\mu \mathrm{m}$ ) was measured as the mean of the smallest axis of the ellipse on the different sections of the vessel.

2. Recanalization, defined as the presence of a neo-lumen in the vessel containing red blood cells and lined by endothelial cells on both sides was evaluated.

3. Percentage of the surface of the artery occluded defined as the relative proportion of the occluded area as a percentage of the total area internal to the internal elastic lamina was evaluated. 
4. Percentage corresponding to the surface occupied by thrombus / metal / hydrogel in the vessel lumen defined as the relative proportion of the thrombus area, the metal area and the hydrogel area as a percentage of the total area was evaluated. The specific surface of the fibers could not be evaluated separately. Due to the thickness of the section, several fibers overlap making it difficult to focus on the fibers situated in the same plan. To obtain the surface percentage of tissue, the digital images were converted to TIFF images and were analysed using GIMP software.

5. Inflammatory cells in contact with the coil, in the vessel wall and in the surrounding tissue were assessed as follows: At the interface with implants, the thickness of inflammatory cells layers around the fibers or the gel was measured in five different sites. Thickness was measured as follows: Absent $(0 \mu \mathrm{m})$, minimal $(1-50 \mu \mathrm{m})$, mild (51$100 \mu \mathrm{m})$ or severe (> $100 \mu \mathrm{m})$.

In the vessel wall and in the surrounding tissue, the inflammatory reaction was defined as absent, minimal (few inflammatory cells), mild (scattered inflammatory cells), moderate (diffuse inflammatory cells) or severe (dense accumulation of inflammatory cells).

Statistical analysis

Summary descriptive statistics were expressed as mean \pm standard deviation. The minimal value, maximal value and range were provided when appropriate. Statistical analysis was then performed using Mann-Whitney $\mathrm{U}$ and $\mathrm{Chi}^{2}$ tests, and Spearman correlations. The level of statistical significance was defined as $\mathrm{p}<0.05$.

Results

Catheterization and embolization were successful in all animals. No difference was found between both types of coils for the number and length of 0.035 -inch or 0.018 -inch coils used to occlude the internal iliac and the renal arteries.

Similar angiographic results were found in animals treated with both types of coils at 7 days, confirming the satisfactory initial embolization procedure. For the internal iliac arteries, 6 animals embolized with hydrocoils and 6 animals embolized with fibered coils had completely occluded target arteries (no statistical difference). For the renal arteries, all the animals 
embolized with hydrocoils had persistent occlusion and 5/6 (83\%) animals embolized with fibered coils had complete arterial occlusion (no statistical difference).

At 1 month after the initial embolization, a significant difference between the coils was found. All 12 (6 iliac and 6 renal) arteries (100\%) embolized with hydrocoils were occluded whereas 6 arteries (50\%) embolized with fibered coils were occluded ( $\mathrm{p}=0.0004)$ (Figs 1-2). For the internal iliac arteries, all 6 animals embolized with hydrocoils had completely occluded target arteries (figure 1). Conversely, 3 (50\%) animals embolized with fibered coils had their internal iliac artery patent $(\mathrm{p}=0.0004)$. For the renal arteries, all 6 animals embolized with hydrocoils had complete occlusion of the target arteries. Conversely, 3 (50\%) animals embolized with fibered coils had their renal artery patent $(\mathrm{p}=0.0004)$ (Fig 2).

During the follow-up, one animal died at 3 months from a ruptured femoral artery pseudoaneurysm and had no control angiography but pathological analysis was performed.

At 4 months after the initial embolization, a significant difference between the coils was found. A total of $8 / 10(80 \%)$ arteries embolized with hydrocoils were occluded whereas $3 / 12(25 \%)$ arteries embolized with fibered coils were occluded $(\mathrm{p}=0.01)$. For the internal iliac arteries, all $5(100 \%)$ animals embolized with hydrocoils had completely occluded target arteries (Fig 1). Conversely, 3 (50\%) animals embolized with fibered coils had their internal iliac artery patent $(\mathrm{p}=0.06)$. For the renal arteries, $3 / 5(60 \%)$ animals embolized with hydrocoils had complete occlusion. Conversely, no animal (0\%) embolized with fibered coils had renal artery occlusion $(\mathrm{p}=0.02)($ Fig 2).

A total of 11/12 animals were euthanized 4 months after embolization and one animal was assessed after its death at 3 months. In the animal that died prematurely, a high quantity of blood was found in the abdominal and pelvic cavity. A ruptured pseudo-aneurysm of $7 \mathrm{x} 4 \mathrm{~cm}$ was present at the puncture site. The segment of the renal artery embolized with the coils was sampled, but the segment of the iliac artery containing the coil was not found by the on-call veterinary surgeon.

Macroscopic observation of all the samples showed no sign of arterial wall lesion. Thus, a total of 23 arteries (11 iliac arteries and 12 renal arteries) were embedded in methyl methacrylate.

The mean diameter of occluded vessels was larger for the iliac arteries $(3,390 \pm 903 \mu \mathrm{m}$, minmax: $2,090-5,130 \mu \mathrm{m}$, median: $3,430 \mu \mathrm{m})$ than for the renal arteries $(2,759 \pm 1,019 \mu \mathrm{m}$, minmax: 703-4,350 $\mu \mathrm{m}$, median: 2,540 $\mu \mathrm{m})(\mathrm{p}=0.0824$, Mann-Whitney). The mean diameter of occluded arteries was 2,892 $\pm 1,023 \mu \mathrm{m}$ for fibered coils (range: 703-4,700 $\mu \mathrm{m}$, median: 2,990 $\mu \mathrm{m}$ ) and 3,324 $\pm 946 \mu \mathrm{m}$ for hydrocoils (range: 2,220-5,130 $\mu \mathrm{m}$, median: $2,985 \mu \mathrm{m}$ ) with no 
significant difference between the two groups ( $\mathrm{p}=0.3077$, Mann-Whitney). The mean diameter of the occluded iliac arteries was 3,311 $\pm 738 \mu \mathrm{m}$ for fibered coils (range: 2,090-4,700 $\mu \mathrm{m}$, median: $3,480 \mu \mathrm{m}$ ) and 3,497 $\pm 1,137 \mu \mathrm{m}$ for hydrocoils (range: 2,220-5,130 $\mu \mathrm{m}$, median: $3,045 \mu \mathrm{m}$ ) with no significant difference ( $\mathrm{p}=0.9342$, Mann-Whitney). The mean diameter of the occluded renal arteries was 2,473 $\pm 1,126 \mu \mathrm{m}$ for fibered coils (range: 703-4,180 $\mu \mathrm{m}$, median:

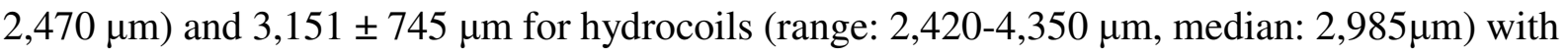
no significant difference ( $\mathrm{p}=0.1266$, Mann-Whitney).

For iliac arteries embolized with 0.035 -inch coils, recanalization was recorded on 8/19 (42\%) cross-sections. For the renal arteries embolized with 0.018-inch coils, 15/19 (79\%) crosssections showed evidence of recanalization. There was a significant difference for the occurrence of recanalization between the two types of artery $\left(\mathrm{p}=0.0202, \mathrm{Chi}^{2}\right)$. Histologic recanalization was observed both in the thrombus and between the vascular wall and the thrombus corresponding to marginal recanalization (Figs 3-5). For each type of artery, there was no significant difference for the occurrence of histologic recanalization between 0.035 -inch hydrocoils and fibered coils ( $\mathrm{p}=0.7288, \mathrm{Chi}^{2}$ and $\mathrm{p}=0.1337, \mathrm{Chi}^{2}$ respectively) (Figs 3-5). The surface percentage of recanalization was higher for fibered coils $(6.5 \pm 8.8 \%$, range: $0-38.0 \%$, median: $3.4 \%)$ than for hydrocoils $(1.8 \pm 3.5 \%$, range: $0-13.9 \%$, median: $0.1 \%)$ although not significantly different $\left(\mathrm{p}=0.0585, \mathrm{Chi}^{2}\right)$.

The mean surface of vessel occlusion was significantly higher for iliac arteries $(96.7 \pm 8.9 \%$, range: $61.9-100 \%$, median: $100 \%)$ than for renal arteries $(94.2 \pm 5.3 \%$, range: $82.9-100 \%$, median: 95.8\%) ( $\mathrm{p}=0.0076$, Mann-Whitney). The mean surface of occlusion of the iliac arteries was $94.7 \pm 11.5 \%$ for fibered coils (range: $61.9-100 \%$, median: $100 \%$ ) and $99.4 \pm 1.0 \%$ for hydrocoils (range: 97.1-100\%, median: 100\%) ( $\mathrm{p}=0.5089$, Mann-Whitney). The mean surface of occlusion of the renal arteries was lower for fibered coils $(92.2 \pm 5.1 \%$; range: 82.9-100\%, median: $92.5 \%)$ than for hydrocoils $(96.8 \pm 4.7 \%$; range: $86.0-100 \%$, median: $98.1 \%)$ $(\mathrm{p}=0.0287$, Mann-Whitney).

For fibered coils, the occlusion plug was composed of thrombus and metal for $77 \%$ and 23\%, respectively (Figs 4-6). For hydrocoils, 36\% of the surface of the occlusion plug corresponded to thrombus and for 64\% (15\% platinum and 49\% hydrogel) (Figs 3,7). The surface percentage of the plug occupied by thrombus was significantly lower for hydrocoils than for fibered coils $(\mathrm{p}<0.0001$, Mann-Whitney). Moreover, the surface percentage of thrombus was correlated with the surface percentage of recanalization $(\mathrm{p}=0.0181, \mathrm{rho}=0.516$, 
Spearman correlation). The surface percentage of metal was significantly lower for hydrocoils than for fibered coils ( $\mathrm{p}=0.0021$, Mann-Whitney). No degradation of the hydrogel was found. For the iliac arteries, the surface percentage of thrombus was significantly higher for fibered coils (76.3 $\pm 7.0 \%$; range: $59.4-84.7$; median: $76.6 \%)$ than for hydrocoils (36.1 $\pm 12.6 \%$; range: 20.3-53.9\%; median: 31.7) ( $\mathrm{p}=0.0003$, Mann-Whitney) (Figs 3-5). The surface percentage of metal was not significantly different between the two products ( $\mathrm{p}=0.2477$, Mann-Whitney). For the renal arteries, the surface percentage of thrombus was significantly higher for fibered coils (76.8 $\pm 7.8 \%$; range: $62.1-87.4 \%$; median: $77.8 \%)$ than for hydrocoils (35.1 $\pm 5.9 \%$; range: 25.1-43.1\%; median: 34.8\%) (p=0.0003, Mann Whitney) (Figs 6,7). The surface percentage of metal was also significantly higher for fibered coils (23.1 $\pm 7.8 \%$; range: 12.5-37.8\%; median: $22.1 \%)$ than for hydrocoils $(10.6 \pm 4.2 \%$; range: $4.8-18.4 \%$; median: $10.9 \%)(p=0.0013$, MannWhitney).

Regarding inflammation, the cells identified directly in contact with fibers or hydrogel were almost exclusively giant cells, the occurrence of which was significantly higher for hydrocoils $(100 \%)$ than for fibered coils $(40.9 \%)$ (Figs 5,6) $\left(\mathrm{p}=0.0002, \mathrm{Chi}^{2}\right)$. The intensity of the inflammatory reaction was statistically different between the two types of coils ( $<<0.0001$, $\mathrm{Chi}^{2}$ ). For fibered coils, the inflammatory reaction was graded as absent in $59.1 \%$ of vessel sections and minimal in $40.9 \%$ of cases. For hydrocoils, it was graded as minimal in $43.7 \%$ and mild in $56.3 \%$ of vessel sections. No inflammatory cells were observed in the vascular wall or in the surrounding tissue for any artery analyzed.

\section{Discussion}

Coils are widely used when a definitive occlusion of medium-to-large diameter vessels is required. Thus, coils are the main agents used to embolize varicoceles, visceral aneurysms, gastroduodenal arteries before radioembolization or pulmonary arterio-venous malformations (6-8,16-19). Pushable fibered coils are mainly used because of their wide availability and low cost. Cross-sectional occlusion results from the embolic agent (metal) and thrombus induced by synthetic fibers. The main limitation associated with fibered coils is recanalization often attributed to clot resorption $(10,20)$. Hydrogel-coated coils have been developed to address this issue. The outer polymer layer of the coil is designed to expand after exposure to blood with approximately $90 \%$ expansion after 20 minutes (20). While it is not expected that the hydrogel will fill $100 \%$ of vessel lumen, the amount of space filled is expected to be significantly greater 
than for bare platinum coils or fibered coils. In experimental studies of phantom aneurysms, it has been shown that compared with bare platinum coils, hydrogel-coated coils prevented formation of a thrombus due to inhibition of fibrin network formation by the hydrogel $(10,11)$. It has also been recently reported that the amount of thrombus was lower after embolization with hydrocoils than with fibered coils (14). In the present study, less thrombus was found 4 months after embolization using hydrocoils than using fibered coils. Due to reduction in arterial flow when the first coil is placed, there is a competitive process between thrombus formation and gel expansion accounting for the presence of thrombus even when hydrocoils are used.

For the endovascular treatment of cerebral aneurysms, coated coils were developed to reduce recurrence and have been in clinical use for 10 years $(9,12,13)$. Initial use of hydrocoils in human resulted in significantly increased initial occlusion rates while the risk of secondary aneurysm rupture was reported to be as low as or lower than that for bare platinum coils $(9,12)$. In the HELPS randomized trial, fewer patients embolized with hydrocoils than those embolized with bare platinum coils had an adverse outcome related to recanalization of treated cerebral aneurysms (13).

In the present study, significantly reduced recanalization rates were identified at angiography using hydrocoils compared to fibered coils at 1 month and 4 months. Of note, recanalization was more frequent in the renal arteries than in the iliac arteries for both types of coils probably because soft microcoils have reduced radial force compared to 0.035 -inch coils (14). This may lead to secondary coil compaction and delayed recanalization $(12,17)$. This phenomenon is a well-known mechanism accounting for delayed recanalization of cerebral aneurysms (12). In the short-term, most clinical studies have not demonstrated higher rates of recanalization with fibered coils compared to hydrocoils. Maleux, et al compared hydrogelcoated microcoils to fibered microcoils in the prophylactic embolization of the gastroduodenal arteries before radioembolization and did not report any case of recanalization of the target arteries (7).

In the present study, no recanalization of internal iliac arteries embolized with 0.035 inch hydrocoils was found. The reduction in the amount of initial thrombus reduces the risk of recanalization and may improve long-term outcomes (14). When long-term occlusion of target vessels is mandatory in young patients or for specific indications such as embolization of pulmonary arterio-venous malformations, 0.035-inch hydrogel-coated coils may have an added value $(18,19)$. These angiographic findings were confirmed by pathological analysis. The mean surface of vessel occlusion was higher for iliac arteries than for renal arteries with both types 
of coils. These findings suggest that, when a safe access to the target artery can be achieved with a regular catheter, 0.035 -inch coils should be favored to reduce the risk of recanalization. The use of soft 0.018 -inch coils should therefore be limited to situations when a microcatheter is required including tortuous anatomy, distal catheterization or superselective filling of an aneurysm.

One of the potential side-effects related to hydrogel added to the coil is inflammatory reaction or gel degradation. In experimental studies of embolization with hydrocoils in animals, only minimal inflammatory reaction was found $(14,20)$. In the present study, minimal inflammation was also found at 4 months after embolization with both types of coils. However, there were more inflammatory cells after embolization with hydrogel-coated coils even when no damage to the arterial wall nor degradation of the hydrogel were observed.

The present study has several limitations. Recanalization was evaluated after embolization of normal vessels and no experimental model of tumors nor aneurysms was used. Follow-up duration was limited to 4 months which may not be long enough to draw definitive conclusions for clinical practice.

In summary, compared with fibered coils, hydrocoils were associated with lower recanalization rates at angiography and pathology at 4 months after embolization particularly when 0.018 coils were used. The difference in the mechanism of initial occlusion with less thrombus formation associated with hydrocoils may be the main explanation. In addition, microcoils regardless of their type were associated with higher recanalization rates than macrocoils due to an increased risk of secondary compaction. Favoring macrocoils over microcoils for occlusion of large-to-medium size vessels should therefore be recommended. 


\section{References}

1. Medsinge A, Zajko A, Orons P, Amesur N, Santos E. A case-based approach to common embolization agents used in vascular interventional radiology. AJR Am J Roentgenol 2014; 203: 699-708.

2. Koebbe CJ, Veznedaroglu E, Jabbour P, Rosenwasser RH. Endovascular management of intracranial aneurysms: current experience and future advances. Neurosurgery 2006; 59 (5 Suppl 3): S93-102.

3. White RI, Pollak JS. Controlled delivery of pushable fibered coils for large vessel embolotherapy. Vascular embolotherapy: general principles. Springer, New-York, 2006, pp 35-42.

4. Golzarian J, Siskin GP, Sharafuddin M, Mimura H, Coldwell DM. Embolization tools. In Golzarian J, Sun S, Sharafuddin MJ. Vascular embolotherapy: general principles. Springer, New-York, 2006, pp 15-33.

5. Ding YH, Dai D, Lewis DA, Cloft HJ, Kallmes DF. Angiographic and histologic analysis of experimental aneurysms embolized with platinum coils, Matrix, and Hydrocoil. AJNR Am J Neuroradiol 2005; 26: 1757-1763.

6. Nambiar AP, Bozlar U, Angle JF, Jensen ME, Hagspiel KD. Initial clinical experience with biopolymer-coated detachable coils (HydroCoil) in peripheral embolization procedures. J Vasc Interv Radiol 2008; 19: 995-1001.

7. Maleux G, Deroose C, Fieuws S, et al. Prospective comparison of hydrogel-coated microcoils versus fibered platinum microcoils in the prophylactic embolization of the gastroduodenal artery before yttrium-90 radioembolization. J Vasc Interv Radiol 2013; 24: 797-803.

8. Greben CR, Axelrod DJ, Charles H, Gandras EJ, Bank M, Setton A. Treatment of posttraumatic aortic pseudoaneurysms using detachable hydrogel-coated coils. J Trauma 2009; 66: 1735-1738. 
9. Cloft HJ, HEAL Investigators. HydroCoil for Endovascular Aneurysm Occlusion (HEAL) study: 3-6 month angiographic follow-up results. AJNR Am J Neuroradiol 2007; 28: 152-154.

10. Reinges MH, Krings T, Drexler AY, et al. Bare, bio-active and hydrogel-coated coils for endovascular treatment of experimentally induced aneurysms. Long-term histological and scanning electron microscopy results. Interv Neuroradiol 2010; 16: 139-150.

11. McCoy MR, Cruise GM, Killer M. Angiographic and artefact-free computed tomography imaging of experimental aneurysms embolised with hydrogel filaments. Eur Radiol 2010; 20: 870-876.

12. Gaba RC, Ansari SA, Roy SS, Marden FA, Viana MA, Malisch TW. Embolization of intracranial aneurysms with hydrogel-coated coils versus inert platinum coils: effects on packing density, coil length and quantity, procedure performance, cost, length of hospital stay, and durability of therapy. Stroke 2006; 37: 1443-1450.

13. White PM, Lewis SC, Gholkar A, HELPS trial collaborators. Coated coils versus bare platinum coils for the endovascular treatment of intracranial aneurysms (HELPS): a randomised controlled trial. Lancet 2011; 377: 1655-1662.

14. Fohlen A, Namur J, Ghegediban H, Laurent A, Wassef M, Pelage JP. Peripheral Embolization using hydrogel-coated coils versus fibered coils: Short-term results in an animal model. Cardiovasc Intervent Radiol 2018; 41: 305-312.

15. Laurent A, Velzenberger E, Wassef M, Pelage JP, Lewis AL. Do microspheres with narrow or standard size distributions localize differently in vasculature? An experimental study in sheep kidney and uterus. J Vasc Interv Radiol 2008; 19: 17331739.

16. Padia SA, Geisinger MA, Newman JS, Pierce G, Obuchowski NA, Sands MJ. Effectiveness of coil embolization in angiographically detectable versus non-detectable sources of upper gastrointestinal hemorrhage. J Vasc Interv Radiol 2009; 20: 461-466. 
17. Yasumoto T, Osuga K, Yamamoto H, et al. Long-term outcomes of coil packing for visceral aneurysms: correlation between packing density and incidence of coil compaction or recanalization. J Vasc Interv Radiol 2013; 24: 1798-807.

18. Laborda A, Medrano J, de Blas I, Urtiaga I, Carnevale FC, de Gregorio MA. Endovascular treatment of pelvic congestion syndrome: visual analog scale (VAS) longterm follow-up clinical evaluation in 202 patients. Cardiovasc Intervent Radiol 2013; 36: 1006-1014.

19. Trerotola SO, Pyeritz RE. PAVM embolization: an update. AJR Am J Roentgenol 2010; 195: 837-845.

20. Guimaraes M, Uflacker R, Garretson JS, et al. Angiographic and histologic comparison of injectable, expansile hydrogel embolic and pushable Azur embolic devices in porcine arteries. J Vasc Interv Radiol 2011; 22: 1619-1624. 


\section{Figure legends}

\section{Figure 1}

Digital substraction angiography of the posterior division of the left internal artery before and after embolization using 0.035 -inch hydrocoils ( 3 coils of $6 \mathrm{~mm}$ x $10 \mathrm{~cm}$, corresponding to 30 $\mathrm{cm}$ of coils). A) Pre-embolization angiography shows the posterior division of the left internal iliac artery. B) Immediate post embolization angiogram demonstrates complete arterial occlusion. C) Post embolization angiogram obtained at 7 days confirms complete arterial occlusion. D) Post embolization angiogram obtained at 4 months demonstrates persistent arterial occlusion. Of note, the contralateral internal iliac artery (not embolized) is enlarged and provides collateral flow to the distal part of the posterior division of the left internal iliac artery. The anterior division of the left internal iliac artery (not embolized) is patent.

\section{Figure 2}

Digital substraction angiography of the right renal artery before and after embolization using detachable 0.018-inch fibered coils ( 2 coils of $8 \mathrm{~mm}$ x $15 \mathrm{~cm}$ and 1 coil $8 \mathrm{~mm}$ x $10 \mathrm{~cm}$ corresponding to $40 \mathrm{~cm}$ of coils). A) Pre-embolization angiography of the right renal artery. B) Immediate post embolization angiogram demonstrates complete arterial occlusion. C) Post embolization angiogram obtained at 7 days confirms complete arterial occlusion. D) Post embolization angiogram obtained at 1 month demonstrates complete recanalization of the renal artery. Of note, coil compaction accounting for both central and marginal recanalization is identified E) Post embolization angiogram at 4 months shows persistent complete recanalization of the right renal artery.

\section{Figure 3}

Photographs of tissue sections of 0.035-inch hydrocoils occluding an iliac artery at 4 months. Complete occlusion is visible. The coil (red arrows) represented $22 \%$ of the lumen surface, the hydrogel (green stars) represented 51\% and thrombus (red stars) represented 27\%. Artefactual detachments are seen around the coil loops. 


\section{Figure 4}

Photographs of tissue sections of 0.035-inch fibered coils occluding an iliac artery at 4 months. Complete occlusion is visible. The coil (red arrows) represented $21 \%$ of the lumen surface and thrombus (red stars) represented 79\%. Dacron fibers are difficult to identify.

\section{Figure 5}

Photographs of tissue sections of 0.035-inch fibered coils occluding an iliac artery at 4 months. The coil (arrows) represented 24\% of the lumen surface and thrombus (red stars) represented $76 \%$. Dacron fibers are difficult to identify. Recanalization corresponding to $2 \%$ of the lumen is seen $(R)$.

\section{Figure 6}

Photographs of tissue sections of 0.018 -inch fibered coils occluding a renal artery at 4 months. The coil (red arrows) represented 14\% of the lumen surface and thrombus (red stars) represented $86 \%$. Recanalization corresponding to $9 \%$ of the lumen is seen (R).

\section{Figure 7}

Photographs of tissue sections of 0.018-inch hydrocoils occluding a renal artery at 4 months. The coil (red arrows), the gel (green stars) and thrombus (red stars) represented 10\%, 58\% and $32 \%$ of the lumen surface. Recanalization corresponding to $4 \%$ of the lumen is seen (R). 


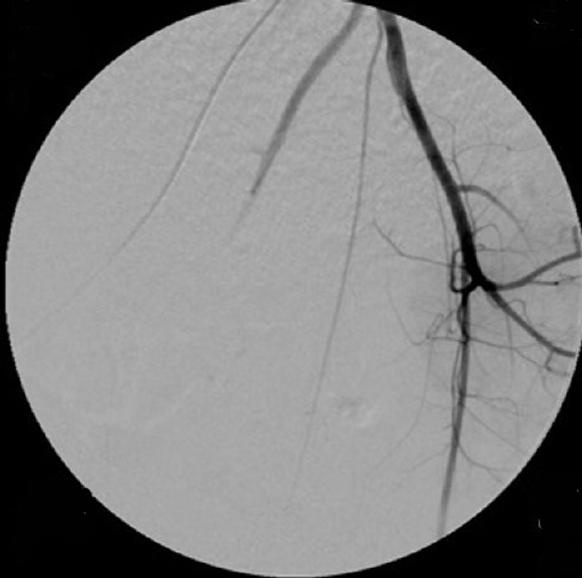




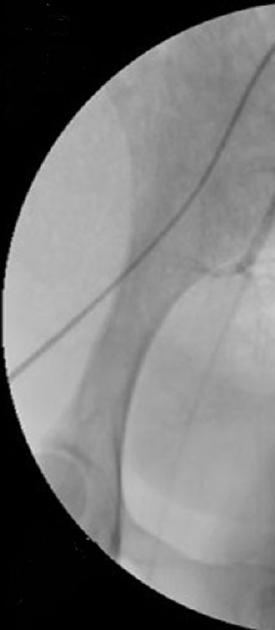




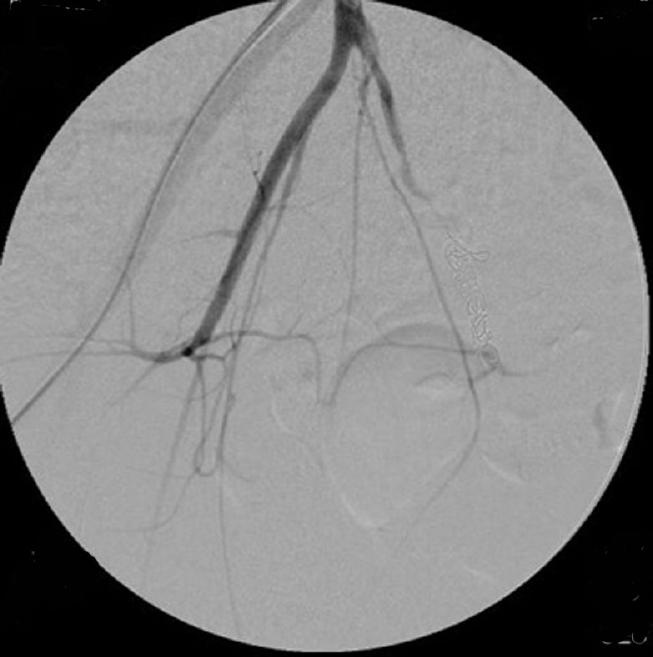




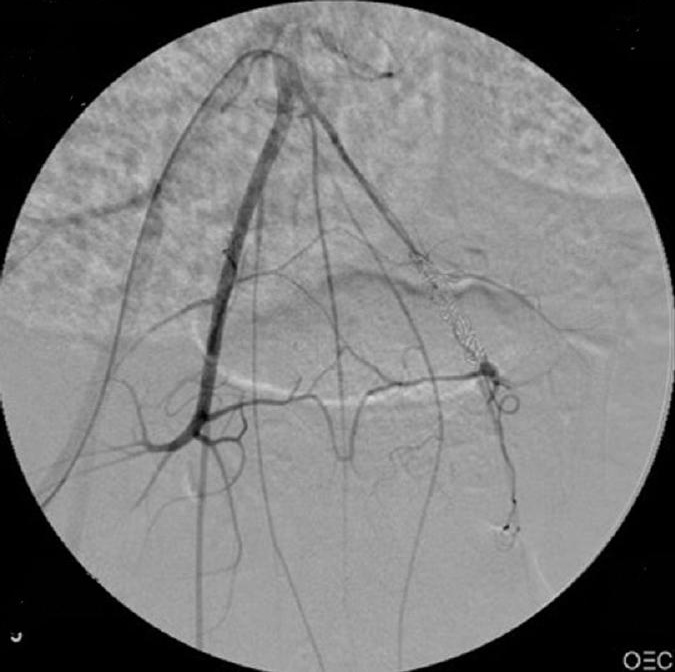




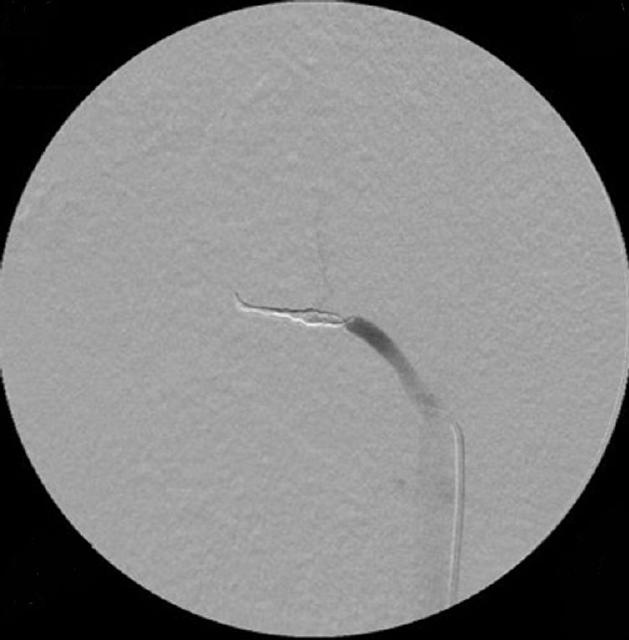




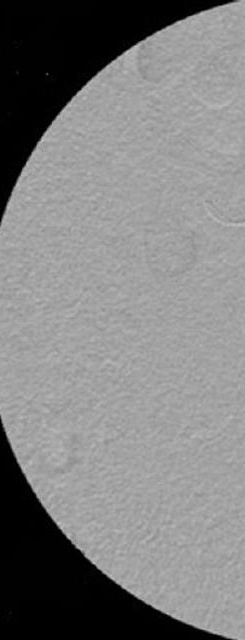




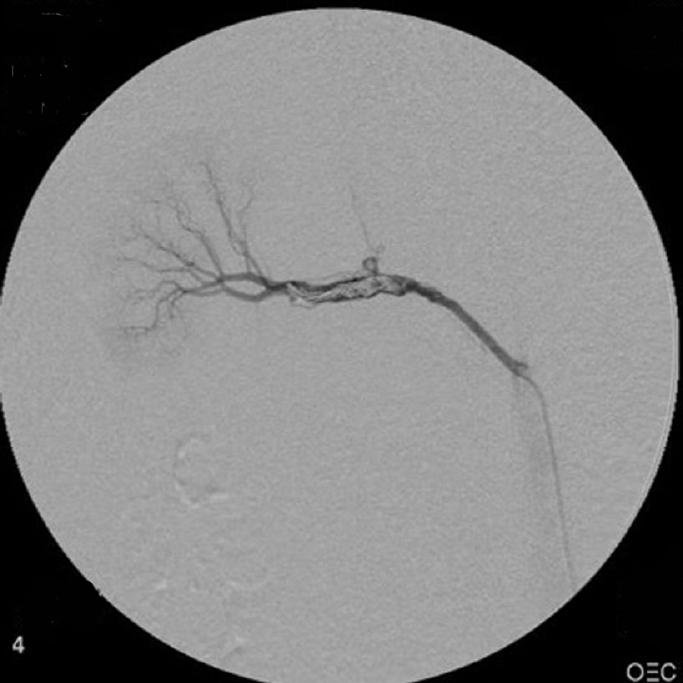





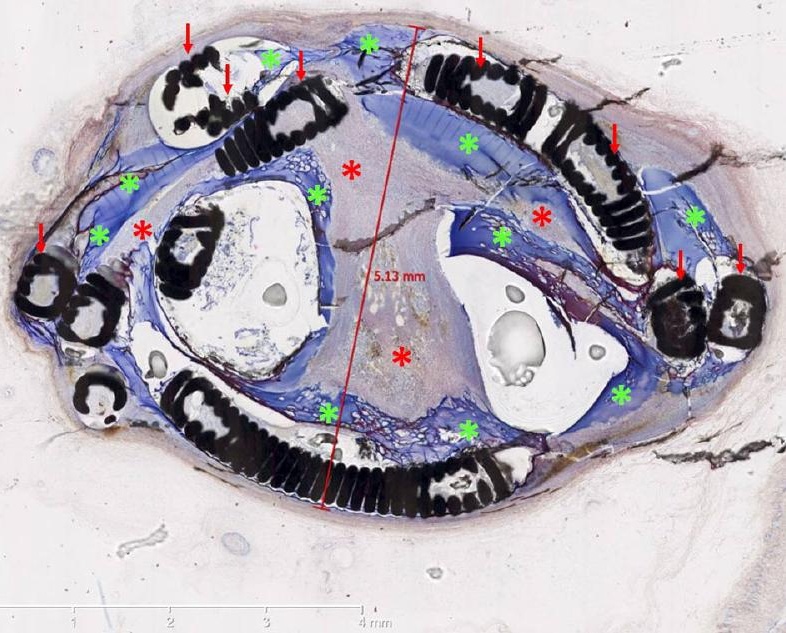


*

(5).

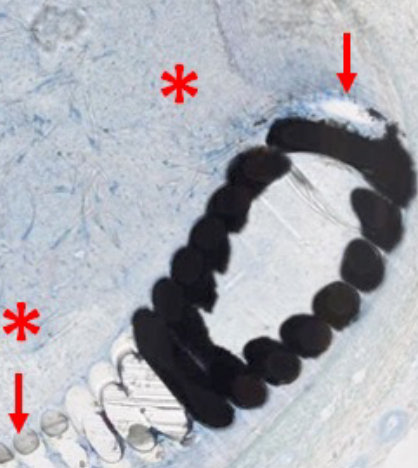

A.

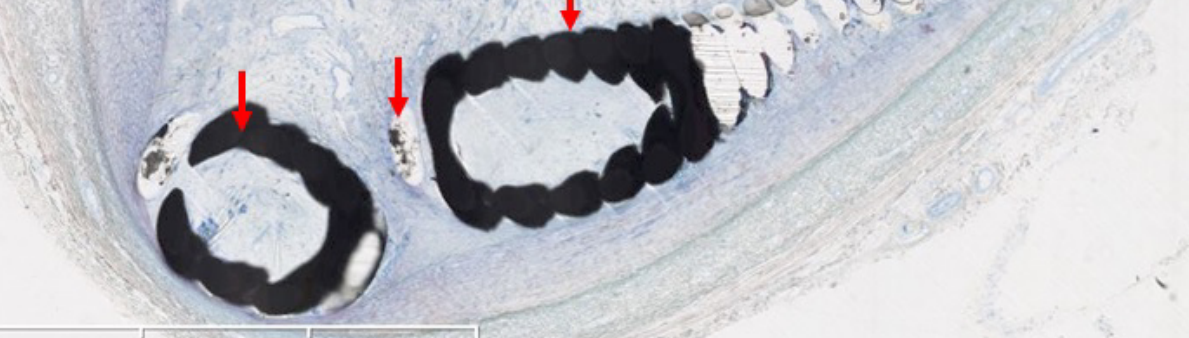




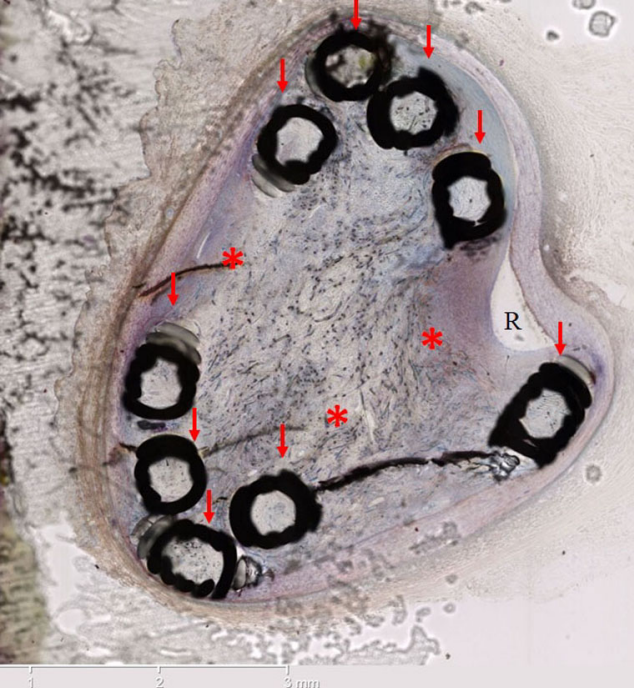




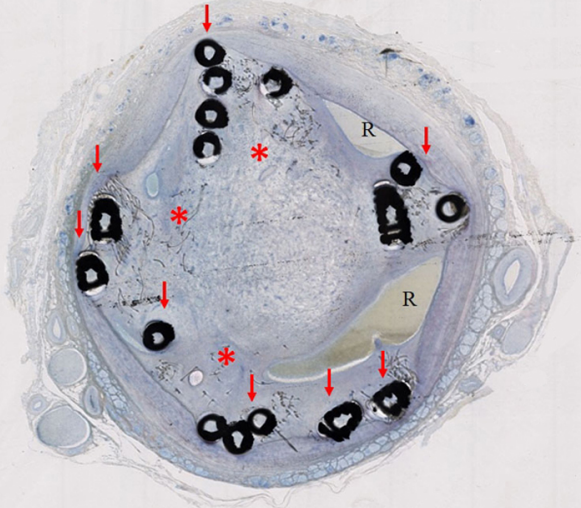

